\title{
PEMBUATAN BIOETANOL DARI MINUMAN SERBUK AFKIR
}

\author{
Wiludjeng Trisasiwi \\ Program Studi Teknik Pertanian, Jurusan Teknologi Pertanian, Fakultas Pertanian, Universitas Jenderal \\ Soedirman, Purwokerto \\ Email: wiludjengsiwi@yahoo.com
}

\begin{abstract}
Bioethanol can be made from three kinds of materials which contains glucose, starch, and cellulose. The creation of bioethanol from glucose substance considered the easiest because only needs two-stage process, fermentation and distillation. Nowadays, the creation of bioethanol from glucose and starch creates new problem due to the demand of the glucose and starch for food needs. Therefore, the non-food sources bioethanol should be found. One of them is from expired date powder beverage. The purpose of the research is to compare the bioethanol creation process using two kinds of distillation equipment. The analysis consist of yield and the purity of the bioethanol. Fermentation is carried out for 14 days using a $0.5 \%$ Fermipan yeast, Urea and TSP fertilizers. One time distillation using equipment with controlled temperature about $78^{\circ} \mathrm{C}$ for 6 hours produced bioethanol yield $20 \%$ and $95 \%$ purity. The simpler distillation tools without temperature controls, due $21.5 \%$ bioethanol, with $80 \%$ purity in twice distillation process. It can be concluded that controlled temperature at the ethanol's boiling point during the distillation process, produces higher yield and purity of the bioethanol also faster processing time. If the distillation temperature is too high, there will be lots of evaporated bioethanol to the ambient and water will evaporated and condensed, so the ethanol purity will be lesser.
\end{abstract}

Key words: bioethanol, distillation, expired date powder beverage, purity, yield.

\section{PENDAHULUAN}

Sejak harga Bahan Bakar Minyak (BBM) melonjak pada bulan September 2005, wacana tentang energi alternatif pengganti BBM semakin mengemuka. Indonesia memiliki potensi energi baru dan terbarukan yang besar, diantaranya dari energy sebesar biomassa 50 GW. Disebutkan dalam Sasaran Kebijakan Energi Nasional yaitu terwujudnya energi mix yang optimal pada tahun 2025, bahwa peranan energi Bahan Bakar Nabati (biofuel) menjadi lebih dari 5\% terhadap konsumsi energi nasional. Pemerintah juga mewajibkan minimal pemanfaatan bioetanol (E100) per Januari 2025 sebagai berikut: untuk transportasi PSO 15\%, untuk transportasi non PSO 15\%, dan untuk industri dan komersial $15 \%$. Hal tersebut mendorong para peneliti di bidang energi untuk mencari lebih banyak lagi bahan baku untuk pembuatan bioetanol.

Bioetanol $\left(\mathrm{C}_{2} \mathrm{H}_{5} \mathrm{OH}\right)$ adalah cairan biokimia yang dibuat dengan proses fermentasi gula dari sumber karbohidrat menggunakan bantuan mikroorganisme. Secara umum, produksi bioetanol mencakup 3 (tiga) rangkaian proses, yaitu: persiapan, fermentasi, dan pemurnian. Tahap pertama meliputi persiapan bahan baku, dari bahan bergula, tepung atau selulosa. Tahap kedua fermentasi, pada tahap ini dilakukan penambahan enzim berupa ragi atau yeast pada gula sederhana (glukosa dan sebagian fruktosa) untuk menghasilkan etanol dan $\mathrm{CO}_{2}$ pada kisaran suhu $27{ }^{\circ} \mathrm{C}$ sampai $32{ }^{\circ} \mathrm{C}$. Tahap adalah distilasi, untuk memisahkan etanol dari beer (campuran etanol dan sebagian besar adalah air).

Beberapa permasalahan yang dihadapi Usaha Kecil Menengah (UKM) 
bioetanol adalah kualitas bioetanol yang masih relatif rendah yaitu kadar etanolnya masih rendah sekitar $70 \%$ meskipun proses distilasi sudah diulang dua atau tiga kali, sehingga harga jual bioetanol tidak dapat tinggi. Tujuan dari penelitian ini adalah menentukan rendemen bioetanol yang lebih tinggi dari dua alat distilasi, yaitu alat distilasi sederhana yang dimiliki UKM dan alat distilasi kolom.

\section{METODE PENELITIAN}

Penelitian dilakukan di lokasi UKM Bioetanol di Desa Cipete, Kecamatan Cilongok, Kabupaten Banyumas, dan di Laboratorium Teknik Sistem Termal dan Energi Terbarukan, Fakultas Pertanian, Unsoed. Bahan yang digunakan terdiri atas minuman berbentuk serbuk afkir merk tertentu yang didatangkan dari Semarang, ragi Fermipan, pupuk Urea dan TSP, dan bahan untuk analisis kimia.

Peralatan yang digunakan antara lain tangki/drum fermentasi, distilator, spektrofotometer, dan peralatan gelas untuk analisis kimia. Dalam penelitian ini digunakan dua alat distilasi yaitu: (1) alat distilasi sederhana milik UKM yang suhunya tidak dapat dikontrol dengan pemanas dari kayu bakar dan (2) alat distilasi model kolom yang suhunya dapat diatur, dengan bahan bakar gas LPG. Analisis meliputi: (1) rendemen hasil \% volume bioetanol murni yang dihasilkan terhadap massa bahan baku (v/m) dan (2) kemurnian bioetanol yang mampu dihasilkan oleh alat distilator $\%(\mathrm{v} / \mathrm{v})$

Metode penelitian meliputi tiga tahap sebagai berikut. (1) persiapan bahan baku: minuman berbentuk serbuk afkir sebanyak $130 \mathrm{~kg}$ ditambahkan dengan Fermipan, Urea dan TSP masing-masing 0,5\% dicampur hingga rata; (2) Fermentasi: bahan dimasukkan ke dalam drum plastik, ditutup dan dibiarkan sampai 14 hari; (3) distilasi dengan dua macam alat yaitu menggunakan alat distilasi sederhana dilakukan 2 kali distilasi selama 6,5 jam (distilasi pertama 4 jam, distilasi kedua 2,5 jam); dan alat distilasi kolom satu kali distlasi selama 6 jam

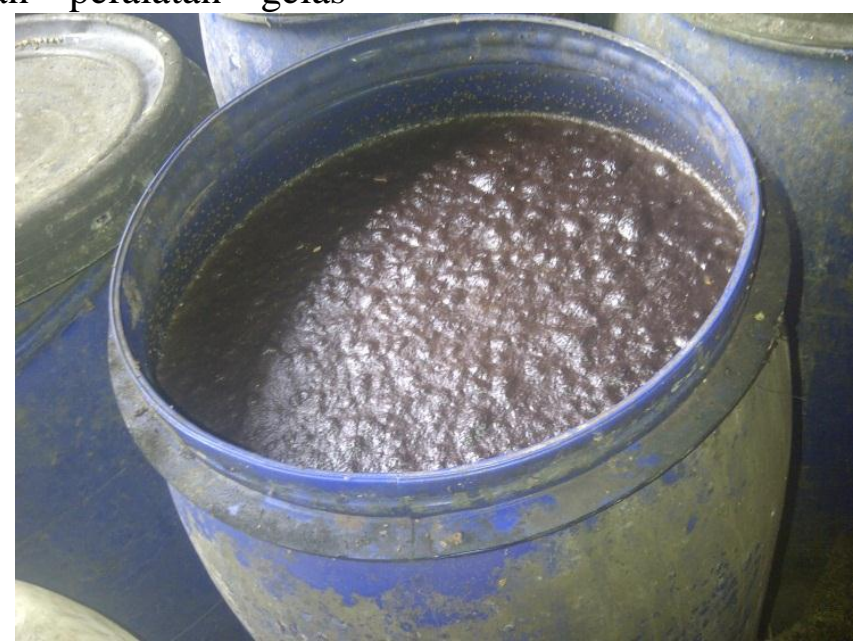

Gambar 1. Fermentasi bahan baku (minuman serbuk) dalam drum. 


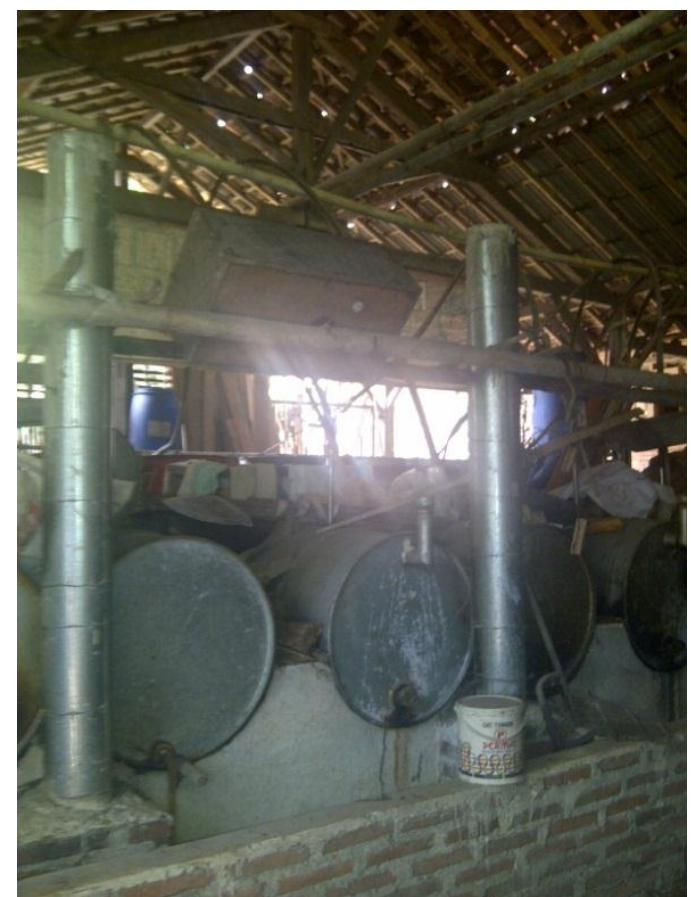

Gambar 2. Tungku bahan bakar kayu pada distilator sederhana.

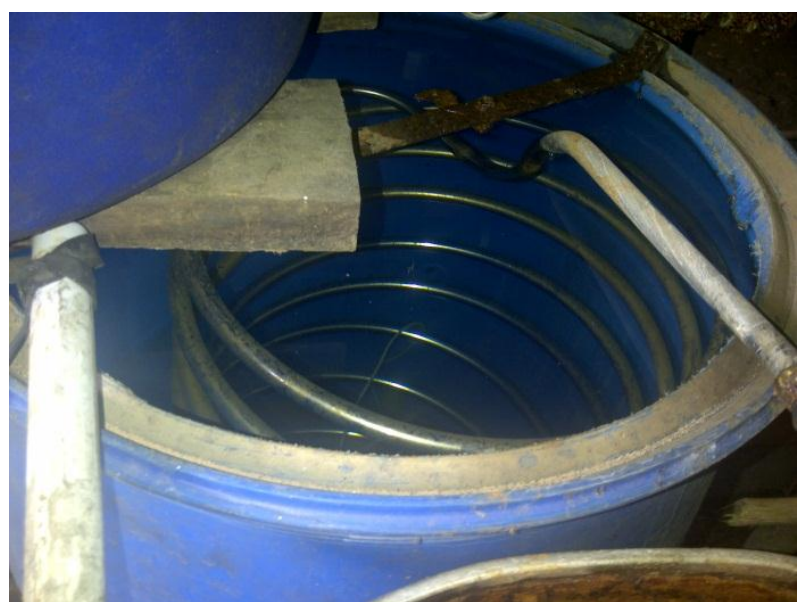

Gambar 3. Kondensor pada distilator sederhana.

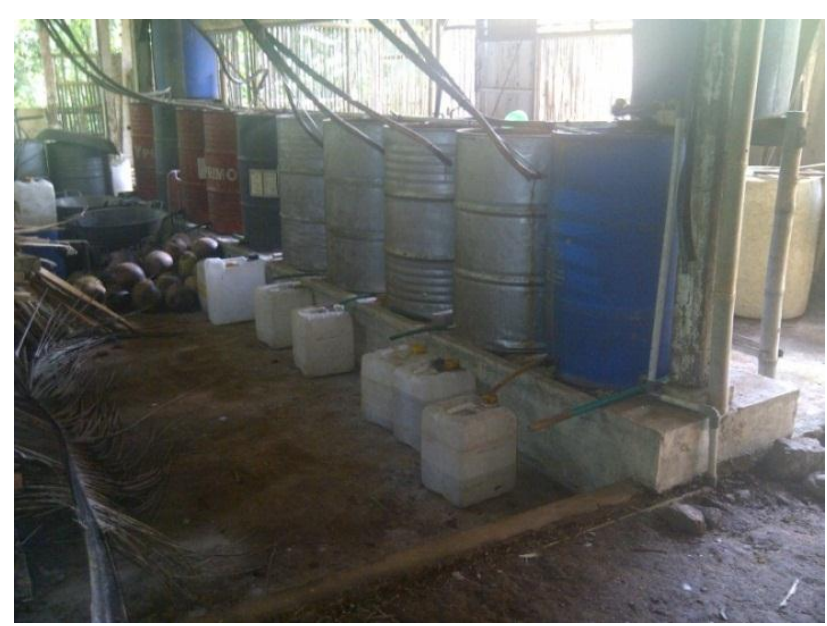

Gambar 4. Kondensor dan penampung bioetanol distilator sederhana. 


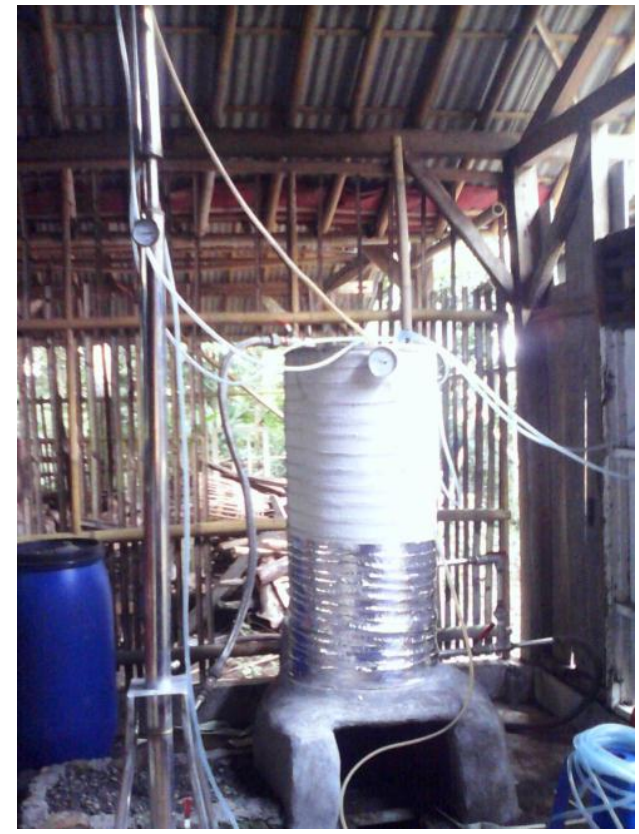

Gambar 5. Distilator kolom.

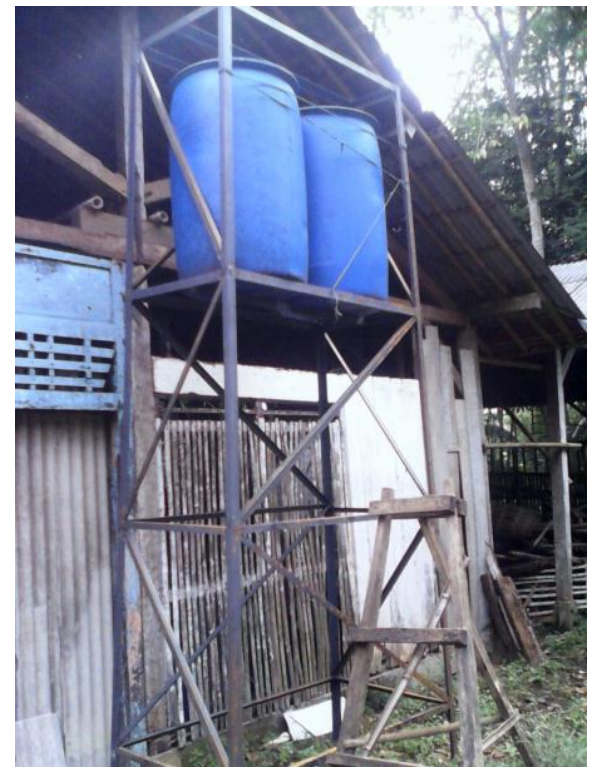

Gambar 6. Tempat bahan hasil fermentasi yg akan didistilasi.

Tabel 1. Rendemen dan kadar bioetanol yang dihasilkan dari dua alat distilasi

\begin{tabular}{ccccccccc}
\hline & \multicolumn{4}{c}{ Rendemen \% (v/m) } & \multicolumn{3}{c}{ Kadar Bioetanol \% (v/v) } \\
\cline { 2 - 9 } Distilator & U1 & U2 & U3 & Rata-rata & U1 & U2 & U3 & Rata-rata \\
\hline Sederhana & 20,5 & 19,5 & 20,0 & 20,0 & 79 & 80 & 81 & 80,0 \\
Kolom & 21,0 & 22,0 & 21,5 & 21,5 & 95,5 & 94,5 & 95 & 95,0 \\
\hline
\end{tabular}

Keterangan: $\mathrm{U}=$ ulangan 
Analisis dilakukan dengan menghitung rendemen bioetanol yang dihasilkan \% v/m (volume bioetanol murni per massa bahan baku), dan kadar bioetanol yang mampu dihasilkan dari kedua alat distilasi \% v/v (volume bioetanol murni per volume bioetanol yang mampu dihasilkan oleh alat distilasi).

\section{HASIL DAN PEMBAHASAN}

Hasil penelitian dari tiga kali ulangan didapatkan data sebagai berikut.

Tabel 1 menunjukkan bahwa distilasi satu kali menggunakan peralatan kolom dengan suhu dikontrol sekitar $78^{\circ} \mathrm{C}$ menghasilkan bioetanol dengan rendemen rata-rata $21,5 \%$, kemurnian 95\% selama 6 jam proses. Alat distilasi yang lebih sederhana tanpa kontrol suhu, dengan dua kali proses distilasi menghasilkan bioetanol dengan rendemen $20 \%$ dan kemurnian $80 \%$ selama 6,5 jam proses.

Dapat disimpulkan bahwa pengontrolan suhu yang dipertahankan pada titik didih etanol yaitu $78^{\circ} \mathrm{C}$ selama proses distilasi menghasilkan rendemen dan kemurnian bioetanol lebih tinggi dan waktu lebih cepat. Jika suhu terlalu tinggi maka bioetanol banyak yang menguap ke lingkungan dan air banyak yang ikut menguap dan terkondensasi dan bercampur dengan bioetanol sehingga kadar bioetanol yang dihasilkan rendah.

Dibandingkan dengan

\section{KESIMPULAN DAN SARAN}

Alat distilator kolom dengan suhu dapat diatur, berbahan bakar gas LPG dalam satu kali proses distilasi selama 6 jam mampu menghasilkan bioetanol kadar 95\% dan rendemen bioetanol $21,5 \%$. Alat distilator sederhana berbahan bakar kayu bakar dalam dua kali proses distilasi selama 6,5 jam mampu menghasilkan bioethanol kadar $80 \%$ dan rendemen $20,0 \%$.

\section{UCAPAN TERIMA KASIH:}

\begin{tabular}{crrr}
\multicolumn{2}{c}{ Kepada LIPI melalui } & Program \\
Penerapan dan & Pemanfaatan & Ilmu
\end{tabular}

Pengetahuan dan Teknologi Di Daerah (Iptekda) LIPI XVIII Tahun 2015, yang telah mendanai kegiatan dan memberikan bantuan alat distilator kolom.

\section{DAFTAR PUSTAKA}

Peraturan Presiden Nomor 5 tahun 2006 Tentang Kebijakan Energi Nasional.

Peraturan Menteri Energi dan Sumber Daya Mineral Nomor 32 tahun 2008 tentang Penyediaan, Pemanfaatan dan Tata Niaga Bahan Bakar Nabati (Biofuel) sebagai Bahan Bakar Lain.

Trisasiwi, W., A. Margiwiyatno, dan Istiqomah. 2015. Pengembangan Peralatan dan Teknologi Proses Distilasi Bioetanol dan Pembuatan Gula Semut Pada UKM di Kabupaten Banyumas. Laporan Kemajuan Iptekda LIPI. 